\title{
Health Sector Reforms: Implications for Maternal and Child Healthcare in South Africa
}

Fadila Jumare

National Institute for Legislative Studies, Abuja- Nigeria

Ogujiuba, Kanayo

National Institute for Legislative Studies, Abuja- Nigeria Department of Statistics and Population Studies University of Western Cape; Cape Town-South Africa E-mail: kannyog@gmail.com

Stiegler Nancy

Department of Statistics and Population Studies University of Western Cape, Cape Town-South Africa

\section{Doi:10.5901/mjss.2013.v4n6p593}

\begin{abstract}
Generally, public health facilities in developing countries tend to be underfunded and inefficient. In South Africa, these problems have continued even after the introduction of free maternal and child health care policy. It is argued that this policy increased utilization rate and consequently overcrowding of public health facilities. Nonetheless, long waiting times and unavailability of certain drugs continue to serve as major barriers to accessing health facilities in South Africa. Available records and our findings indicate that there is lack of consistent training for health personnel, increasing workload, inadequate physical infrastructure, resources and equipment, which have made it difficult to reduce maternal mortality rates. This paper $x$ rays health reforms in other countries vis-à-vis propositions by international organizations and posits that the free maternal and child healthcare policy in South Africa has been formulated without considering the capacity and resources necessary to implement it. As a result, its implementation only aided in increasing access to public facilities and an improvement in utilization rates with no substantial increase in the quality of the services delivery. The paper concludes that the current health reform have the potential of reducing social exclusion, nonetheless, it must be managed carefully through supportive actions in order to avoid negative impacts on the wider health system and consequent worsening of the health system.
\end{abstract}

Keywords: Health Sector Reform, Maternal and Child Health, Utilization, Efficiency, Capacity

\section{Introduction}

Numerous studies of healthcare systems emphasize the importance of primary healthcare reform as a tool for not only transforming the entire health system but also for ensuring a better life for all (WHO report, 2008: xii, HST, 2008: i \& SAHRC, 2009:10). In addition, the WHO recommends a coherent vehicle to manage the delivery of primary healthcare. In developing countries, governments' failure to produce efficient health service delivery also calls for the need to investigate the situation of public health clinics. Buso (2004:5) states that this phenomenon of government's failure is well documented in official, unofficial documents and media outlets. Nonetheless, the Human Rights Commission confirmed the deterioration of many areas of the public health system such as that of HIVIAIDS (SAHRC, 2007:6). This demonstrates a general challenge for governments to prioritize and manage healthcare in developing countries. In addition, there is growing demand for healthcare leading to rising costs and decreased resources. There is also evidence of variation in clinical practice and growing dissatisfaction from public health users (Schneider, 2002). One of the indicators of progress towards achievement of the Millennium Development Goals (MDGs) is the effective and equitable delivery of public services (MDG monitor fact sheet, 2007). Howbeit, it is doubtful that developing countries could meet 
the yardstick by 2015. Continued support for family planning programs and efforts to improve access to antenatal care are known to have significant effect in reducing maternal and child mortality rates. As a result of family planning efforts of governments, there has been declining global fertility rates meaning that family planning, especially increased access to contraceptives can help prevent unwanted pregnancies, reduce the risk of costly abortions and consequently mortality rates. Based on data provided by Davanzo \& Adamson D (1998) from a 30-year trend data, it is evident that abortion has declined in Hungary with increased contraceptive use as do data from other settings such as South Korea. Evidence from Russia and Kazakhstan also shows declines in abortion in the 1990s as contraceptive services have expanded.

Similarly, data provided by AbouZahr \& Wardlaw (2004) on antenatal care visits has shown that in the late 1990s and 2000-2001 just over 70\% of women worldwide have at least one antenatal visit with a skilled provider during pregnancy. In the industrialized countries coverage was extremely high, indicating considerable success for programmes aimed at making antenatal care available in these regions compared to $68 \%$ in the developing countries.

However, Koblinsky et al (1999:399) argue that, ten years after the safe motherhood initiative, some 585,000 women are dying annually from obstetric complications and associated diseases. Malaysia's move to ensure delivery by professional attendants in basic essential obstetric care facilities has been successful in reducing home deliveries. By $1995,88 \%$ of home births were moved to hospital deliveries which substantially reduced maternal mortality. In Sri Lanka, $94 \%$ of births occurred in hospitals. Koblinsky et al note that a successful transition requires free transportation and services for all, awareness of services in the communities and the provision of quality care for all.

In Australia, Japan, New Zealand and most countries in Northern and Western Europe and North America, the maternal mortality rates are usually under 10 per 100,000 of the population. This is as a result of providing deliveries by professional attendants in comprehensive essential obstetric care facilities. In developing countries however, having skilled professionals in obstetric care facilities does not guarantee a reduction in maternal mortality. This is because the services provided are of very low quality. Koblinsky et al, (1999:403) note that in Romania, the mortality rate was 180 per 100,000 births in the 1980s because of unsafe abortions. In addition, Mexico city had a mortality rate of 114 per 100,000 births in 1998. 85\% of these deaths were attributed to incorrect and inappropriate decisions regarding diagnosis and surgical case misjudgments. Therefore it can be inferred that quality assurance mechanisms are supposed to be in place to ensure that skilled personnel are available and are giving the proper care. It is also necessary to ensure that the required equipments are functioning including consistent availability of supplies.

Therefore, measures to prevent complications through the provision of prenatal care, family planning and health education are deemed much less effective and priority should be given to the establishment and upgrading of obstetric care at the first referral level. This would ensure that complications in delivery are managed effectively as they arise. However, Sai \& Measham (1992: 478) propose that other approaches should be maintained in conjunction with obstetric care because they play a large role in increasing the utilization of obstetric facilities. In conclusion while the more industrialized countries were able to reduce maternal mortality through the use of professional obstetric care, the outcome of this is not yet seen in developing countries. Goodburn \& Campbell (2002: 917) indicated that in settings where resources are few, it is less clear how these interventions can be achieved. Finally, Weil \& Fernandez (1999:1942) note that one of the reasons mentioned for countries not meeting the desired outcomes of safe motherhood is that decision makers have not made decisions appropriate to their countries. The authors made mention of accessibility in all of the safe motherhood interventions which show the magnitude of its importance.

Nonetheless, the reduction in maternal mortality has been adopted as an International Development Goal by the United Nations (UN), the Organization for Economic Cooperation and Development (OECD), the International Monetary Fund, and the World Bank and endorsed by 149 heads of states at the Millennium Summit in 2000 (Abou Zahr \& Wardlaw, 2001: 561). Maternal mortality is expected to reduce by 75\% in 2015 (Goodburn \& Campbell, 2001:917). An indicator associated with maternal mortality; the percentage of births assisted by a skilled health care worker and in subSaharan Africa, or coverage of skilled care at delivery has stagnated in Sub-Saharan Africa. Therefore, optimism regarding trends 100 in maternal mortality remains disquieting (AbouZahr \& Wardlaw, 2001: 561). The situation in large parts of sub-Saharan Africa is alarming, with unchanged or declining levels of coverage of skilled care for women during the crucial period of childbirth. This is a particular cause for concern in a setting with high prevalence of HIVIAIDS such as South Africa, where the need for skilled care during labour and childbirth is critical (Abou Zahr \& Wardlaw, 2001: 573).

This paper investigates the question of the effect of South Africa's health sector reforms on the maternal and child healthcare services provided in public health clinics; which is achieved by employing principles such as efficiency, equity and improved access to primary healthcare services in developing countries. The aim of this paper is to:

I. Assess the impact of health sector reforms on maternal and child health care services and indicate the implications of this on the quality of primary healthcare in public health clinics; and 
II. Drawing upon good practice studies in maternal and child health programmes, this paper highlights the strengths and weaknesses of the reforms in South Africa with a specific focus on public health clinics.

\section{Brief Review of Related Literature}

The available literature points out the features of health sector reform in general and how they are applied in different countries. Some of the authors include: Cassells (1995), Berman (1995), Bloom (1997) and Whitehead et al, (2001). Others who have focused on the effects of health sector reform on maternal and child health include: Hardee \& Smith (2000), Lubben et al (2002), Standing (2000), Mills et al (2002), Berman \& Bossert (2000), Murky \& Klugman (2004), Berer (2003) and Dmytraczenko et al (2003). Concurrent with the goals of the WHO, Berman (1995:15) describes health sector reform as a sustained purposeful change to improve efficiency, equity and effectiveness of the health sector. Health sector he says is the totality of policies, institutions and actors that provide healthcare. The United Nations recognizes that countries must implement reproductive health in the context of health sector reform (Hardee \& Smith, 2000:11).

A number of factors have prompted the need for health sector reforms in developing countries. This includes firstly the movement from state controlled economies to market oriented economies. In addition, insufficient funding for health in times of financial crisis, the lack of basic health services for many citizens and the poor quality, low accountability and inefficiency of existing health services gave rise to the need for health sector reforms in developing countries (Dmytraczenko et al, 2003:667). Standing (1997:1), notes that of particular concern is the effect that reforms based on cost recovery have on the poor. According to the report of the World Health Organization (2000), five goals are critical to health sector reforms three of which are relevant for this paper. These include: Efficiency, quality and equity. Efficiency refers to the need for health improvements to be achieved at the lowest possible cost. Quality on the other hand requires that appropriate and safe clinical services, adequate amenities, skilled staff and essential drugs, supplies and equipment are available. Equity ensures that health resources are distributed fairly so that nobody is denied access to essential care. Healthcare reforms in many countries took the form of changes in financing, privatization and integration of service delivery amongst others.

\subsubsection{Changes in Financing}

For middle income countries such as South Africa, Berman (1995:20) suggests that financing strategies might involve more focus on cost containment and reduction of growth in some types of health care consumption. This diverts attention to assuring access to essential services for neglected groups. The desired outcome would be development of a health sector which contributes more to sustainable development on a lower cost trajectory. Some approaches to financing aim to mobilize additional funds for healthcare and channel funds to the most effective uses. This allows more citizens to access health services and increases the quality. Even though this system can improve equity in accessing health services, the issue of quality improvement remains questionable.

As noted by Gilson et al (2003:31-46), the free maternal and child health care policy in South Africa fits into this criterion. This health sector reform framework assumes the form of a resource allocation process that allocates higher budget levels to the most effective and efficient provinces. However with shrinking resources, Hardee \& Smith (2000:19) cite that the sustainability of providing free health services is no longer a certainty. An alternative form of financing health is known as the cost sharing/cost recovery. This involves imposing user fees for some or all health services as a way to get clients to share the expense of services. Achieving this objective involves establishing waiver systems to exempt the poorest clients from payment, but putting such systems into practice has proven difficult (Dmytraczenko et al, 2003:667).

Gilson \& Mclyntre (2000) note the impact of user fees on households. User fees can encourage inappropriate self treatment and use of partial drug may act as a barrier to early use, or perhaps any use, of health facilities. By increasing the costs associated with illness, even a small level of fee can contribute to the impoverishment of vulnerable households. They may need to sell key assets, cut down on other necessary expenditures, or borrow, often at exorbitant interest rates, to pay for health care and cope with the loss of income resulting from illness. In addition, fees add to the other immense barriers, such as distance and abusive treatment by healthcare providers, that poor people face when seeking health care (Gilson \& Mclyntre, 2000).

Borghi \& Ensor posit that much greater resources are needed to scale up the coverage of maternal health services in order to successfully contain the costs of providing free primary healthcare. For example, it is necessary to increase funding so as to avoid shortages of drugs and medical supplies. It was noted however that the current investment in 
maternal health is insufficient to meet the fifth millennium development goal (Borghi \& Ensor, 2006:1456) in many countries. Therefore health financing strategies all have their strengths and weakness and governments need to be careful so as not to incur negative impacts of any specific reform strategy.

\subsubsection{Privatization}

Hardee \& Smith (2000:8) propose that family planning has had some successes in encouraging wider participation of private and commercial sectors in health service provision. Some countries regulate the behavior of private sector health providers in the distribution of drugs because unregulated private sector provision may do more harm than good. For example they can impose exorbitant prices to the health service users. Berhmann \& Knowles, 1999 in Hardee \& Smith (2000:17) note that while there are some cases where government health service provision is better than the private sector, the reverse is generally true. For example, Brugha \& Zwi (1998:108) argue that in many countries, a high proportion of patients prefer to attend private for profit health providers because they are attributed to having greater ease of access, shorter waiting periods, longer and more flexible working hours, better availability of staff and drugs and more sensitive client-worker attitudes. This implies that health services provided by the private sector are of greater quality.

\subsubsection{Integration of Service Delivery}

Combining separate health services into a single restructured system has been a key initiative in health sector reform. In principle, such a combination can improve services and reduce costs by putting the same infrastructure, equipment, supplies, and personnel to multiple uses. In addition, patients are likely to seek several services at each visit. Integration can improve overall efficiency, but it can also lead to a loss of focus on certain services such as reproductive health because providers must spread their time and resources over a wider range of health services. Experience has shown that conscious efforts are needed to ensure that integration works well. Effective referral systems must be in place, and strong management skills are needed because administrative functions such as planning, budgeting, purchasing, and providing training are more complex under integrated systems than under stand-alone programs (Dmytraczenko et al, 2003:667).

Berer, (2003:7) suggests that integration of health policies and programs is centered on referral linkages between existing service providers or providing two or more services together that were formally provided separately. Maternal and child health, immunization and family planning are examples of integrated care but each of them is often treated as one vertical service. In some countries, maternal mortality has reduced as a result of contraceptive use but deaths from complications of unwanted pregnancies and unsafe abortions have remained high. Integration involves the provision of these services including antenatal and obstetric emergency care services into a single maternity care package Berer, (2003:9). Family planning can also be linked with postpartum services (Hardee \& Smith, 2000:8). These authors also note that integrating family planning and other vertical maternal care services would ensure greater efficiency and effectiveness of service delivery. Integration of reproductive services is also said to reduce duplication, promote sharing of facilities and use workers to perform multiple tasks. Consequently, the cost of providing the services would reduce as in the case of Zimbabwe \& Mexico (Mitchell et al, 1999 in Hardee \& Smith, 2000: 16). The disadvantage of integrating health services is that some services are made to suffer at the expense of others. In addition, where there is lack of training, equipment and supplies, integration does not lead to efficient provision of services and infact a reduction in quality. Askew et al, 1998 in Hardee \& Smith, (2000:7) note that in several African countries, many family planning clinics were not equipped to offer Sexually Transmitted Disease (STD) services and that staff were not sufficiently trained. Therefore there are challenges faced in the attempts to integrate reproductive services which undermine the quality of service delivery in public health facilities.

Kerber et al, (2007) outline the elements that would impede the functionality of safe motherhood or continuum care for the reduction of Maternal, Neonatal and Child deaths. This includes those elements that affect the functionality of health Systems such as human resource capacity, health-facility infrastructure, supply systems, financial resources, government stewardship, district-level management, and monitoring (Kerber, et al, 2007:1637). In addition, the wider health reform strategies that would impact positively on the reduction of maternal mortality include strengthening public management; explicit priority setting for a universal package of assured interventions; decentralization; new methods of generating and managing finances for health and enhancing the role of private providers in national health systems. 


\subsection{Review of Reform Strategies Proposed by International Organizations}

A wide range of specific reform strategies have been proposed for reducing maternal/child mortality based on analysis by international organizations and recent national experience in the richer and poorer countries. Most of the literature on strategies for reducing maternal mortality has focused on safe motherhood strategies and continuum care. The particular concern for this paper is the safe motherhood strategy which was adopted in 1987 at a conference in Nairobi, Kenya. It aims to restore the right to life of more than half a million women every year (Weil \& Fernandez, 1999:1940). Four broad and multifaceted strategies were strictly health related including:

- To provide universal primary healthcare from infancy to adolescence (and thereafter to provide universally available family planning services)

- To provide good prenatal care (including screening for at risk pregnancies)

- To ensure the presence of skilled individuals at deliveries (and thereafter to provide training for those likely to assist at all births both at home and in the hospitals)

- To strengthen the basic obstetric care (at the first referral level) making it accessible to women at risk, in cases of emergency, during pregnancy, delivery and post-partum (Weil \& Fernandez, 1999:1940). According to these authors, "a maternal programme lacking any of these services would be as wobbly as a table with three legs".

Each of these programmes is discussed as follows:

\subsubsection{Family Planning and Elective Abortions}

This is seen as a component of the safe motherhood strategy. About $15 \%$ of deaths occur as a result of abortion related complications. Experience has shown that increased rates of contraceptive use in a community could result in as much as 30\% reduction in maternal mortality (Weil \& Fernandez, 1999:1941).

The World Bank also considers community-based family planning, health and nutrition services and substantial and sustained reduction of the risk of dying while pregnant as a package for continuum of care (Kerber et al, 2007:1360). This relates to the safe motherhood strategies already outlined. According to Kerber et al, (2007:1360), the "continuum of care approach promotes care for mothers and children from pregnancy to delivery, the immediate postnatal period, and childhood, recognizing that safe childbirth is critical to the health of both the woman and the newborn child". Another related continuum is required to link households to hospitals by improving home based practices, mobilising families to seek the care they need, and increasing access to and quality care at health facilities (Kerber et al, 2007:1360). However strategies related to family planning and abortion are not regarded as the best methods of maternal mortality reduction because most maternal deaths occur during or after wanted pregnancies and thus could not be prevented by the use of contraceptives (Weil \& Fernandez, 1999:1941).

\subsubsection{Antenatal Care}

Antenatal Care is also regarded by Bergsjo (cited in De Brouwere \& Lerberghe, 2001:45) as a core component of routine maternal and child health services. It is also noted that it receives the largest budgetary resource in many developing countries. It is considered as one of the four pillars of safe motherhood namely, family planning, clean and safe delivery and obstetric care. A core component of antenatal care mentioned amongst others is the immunization of pregnant women or women of child bearing age. This would prevent maternal and neonatal tetanus. Proper antenatal care can result in substantial reduction in maternal and child mortality. Furthermore the out-patient and outreach service is mentioned as a component of continuum of care (safe motherhood strategy) for reducing maternal mortality. It involves antenatal or postnatal care delivered on a routine basis through static clinics, immunization campaigns or child health days delivered through mobile services. Kerber, et al, (2007:1361) assert that another approach to clinical care consists of individual-oriented case management of mothers, babies, and children with illness or complications, which is typically provided through facility-based care at primary and referral sites.

Prenatal care (antenatal care), which is a component of safe motherhood strategies is also said to have no direct value in the prevention of maternal mortality unless the professionals involved have the necessary equipment, supplies and access to essential obstetric care in the case of complications. The authors report that $80 \%$ of deaths are due to complications for which no prenatal screening was possible. They were due to puerperal sepsis, postpartum haemorrhage and shock (Weil \& Fernandez, 1999:1942). Another safe motherhood strategy cited by Weil \& Fernandez, 
(1999:1942) is referred to as the training of traditional birth attendants. As suggested in the case of family planning and prenatal care, this does not seem to have an impact on maternal mortality reduction unless it is combined with accessible hospital settings or healthcare centers where essential obstetrics care services are available.

\subsubsection{Essential Obstetric Care}

Goodburn \& Campbell, (2002: 917) argue that as a result of the failure of home based practices, the availability, accessibility, use, and quality of essential obstetric care for life threatening conditions; including complications after abortion, need to be improved. In addition Goodburn \& Campbell, (2001:917) suggest that linking safe motherhood programmes to health sector wide approaches would make a sustainable impact on maternal mortality. This means that health system reforms must be accompanied by strategies to increase the availability of skilled attendants at births and improving obstetric care. An obstetric care package according to Goodburn \& Campbell includes:

- Parenteral antibiotics, oxytocics, and anticonvulsants available

- Facilities for manual removal of the placenta if necessary

- Facilities for removal of retained products of conception if necessary

- Assisted vaginal delivery (for example, using vacuum extraction) available

- Facilities for blood transfusion

- Facilities for caesarean section

Campbell et al, (2006:11) also made reference to emergency obstetric care. According to Campbell et al, the capacity to provide adequate and timely emergency obstetric care is the minimum standard a health system is ethically obliged to provide to begin to address maternal mortality. This requires that health centres and hospitals are equipped with essential supplies and drugs so as to deal with emergencies that reach them on time.

Similarly, Weil \& Fernandez, (1999:1942) cite that the availability of obstetric care is the best intervention for preventing maternal morbidity and mortality. Its success depends on the speed of surgical delivery and accessibility to a setting where obstetric care is available. Essential obstetric care is centralized in anesthesia, caesarean sections and blood transfusions to the level of district hospitals. It also requires an efficient referral mechanism and must provide the minimum amount of equipment.

It was also noted by Kerber et al (2007:1360) that these services, such as emergency obstetric care, are the most challenging and costly to provide, but also have the highest potential to save lives. They also propose that clinical care should therefore be available for $24 \mathrm{~h}$ per day, and providers must be adequately trained, equipped, and supervised. Normal childbirth also demands skilled clinical case management and continuous availability of health-care professionals.

\subsection{Conceptual Framework for Assessing the Quality of Service Delivery in Public Health Clinics}

\begin{tabular}{|c|c|c|}
\hline Addressing the barriers to obtaining & \multicolumn{2}{|c|}{ Addressing the barriers to providing health services } \\
\hline Accessibility & Availability & Efficiency \\
\hline $\begin{array}{l}\text { Distance and travel time } \\
\text { Opening times/Clinic hours }\end{array}$ & $\begin{array}{l}\text { Number of } \mathrm{PHC} \\
\text { clinics in a district }\end{array}$ & $\begin{array}{l}\text { Allocation of resources } \\
\text { Referral mechanisms } \\
\text { Utilization of services }\end{array}$ \\
\hline & Range of $\mathrm{PHC}$ & Administrative efficiency \\
\hline Attitude of health providers & services rendered & $\begin{array}{l}\text { Reduction of duplicate structures } \\
\text { including integration of vertically }\end{array}$ \\
\hline Patients' waiting times & $\begin{array}{l}\text { Personnel, } \\
\text { equipment, drug }\end{array}$ & organized programmes \\
\hline cleanliness and safety & supplies and funds & Minimize loss of needed \\
\hline Affordability & & personnel from the system as a \\
\hline $\begin{array}{l}\text { Travel costs to the clinic } \\
\text { Time costs to attend the clinics } \\
\text { Conditions of roads to the clinics }\end{array}$ & $\begin{array}{l}\text { Availability of } \\
\text { emergency service }\end{array}$ & whole (brain drain) \\
\hline
\end{tabular}

Sources: (Evan et al, 2001), (Daniels et al, 2000:7) 
Most of the literature on quality of health care has focused on process indicators. Evan et al, (2001) have outlined a framework for measuring the quality of health systems in terms of a set of desirable outcomes. This can be achieved by setting goals and evaluating the extent to which the health system is contributing to the goals. Therefore the goals set out for the reduction of maternal and child mortality can be measured using this framework. This would reveal the performance of the free primary care policy.

Based on the table, Accessibility refers to the removal of financial (e.g. travel cost) and non financial barriers (e.g. long waiting times) to access health services. Availability on the other hand evaluates health systems according to measures taken to address the poor distribution of drugs, supplies, facilities and personnel (mix and training). Efficiency is measured by establishing whether resources have been allocated appropriately. Refferal mechanisms would minimize the duplicate structures (Daniels et al, 2000:742-744). Minimizing brain drain would also reduce overcrowding in the clinics. It is therefore necessary to have sufficient number of staff to deal with the increased utilization of clinics.

Critical to the quality of primary healthcare are the principles of efficiency, equity and access. Accessibility is the ease with which health services are reached. Access can be physical, financial or psychological, and requires that health services are a priori available. Equity is a dimension closely related to access, although it is also used as a metric to assess health-system financing outcomes and health status. Equity (or equitability) defines the extent to which a system deals fairly with all concerned. Equity, in this context, deals with the distribution of healthcare and its benefits among a people. Efficiency is the system's optimal use of available resources to yield maximum benefits or results (JCAHO, 1997 in Kelley \& Hurst 2006:13). It speaks to a system's ability to function at lower costs without diminishing attainable and desirable results (Donabedian, 2003 in Kelley \& Hurst, 2006:13). Past consensus documents from the Organization for Economic Corporation and Development (OECD) have used the terms "macro-economic" and "micro-economic" efficiency. Macro-efficiency refers to the overall allocation of public and private expenditures in the health system that is overall health spending at the "right" level. In some of the country frameworks, macro-efficiency is alternately termed "sustainability" or "affordability". Micro-efficiency refers to the value for money realized with available resources, i.e. is the health system as productive as possible in light of the system inputs and desired outputs? (Kelley and Hurst, 2006:13).

Equity oriented reforms refer to the increase in efficiency and effectiveness with which health systems reach the poor and disadvantaged and reforms that contribute to the lessened differences in health status (Gwatkin, 2001:720). In other words, equity in primary healthcare refers to the fairness in resource allocations across different areas such as provinces for example, Gilson et.al, (2003:5) describe equity as needs based resource allocation mechanisms in distributing health budgets between geographical areas. Because it emphasized equity through cross subsidization and revenue generation, efficiency would be achieved. Gilson et al, (2003:5) found that by 1999, the Social Health Insurance policy together with the uniform fee schedule in were not implemented in South Africa. This suggests a lack of equity and efficiency. The aim of ensuring equity is to eliminate disparities in health between some disadvantaged groups which are associated with different levels of social advantage as characterized by wealth, power or prestige (Braveman, 2003:182). Accessibility can be measured by determining how affordable the hospital services are. In doing this, the fee removal policy for all primary health care services would be assessed. In discussing access to Antiretroviral treatment in Africa, Loewenson \& McCoy, (2004:242) suggest that access to healthcare services can be achieved by establishing a criteria for explicitly targeting low income groups such as health workers and teachers. This would enhance equity and reduce corrupt practices around treatment. Approaches to enhance access to primary healthcare services would strengthen health systems by ensuring the best allocation of scarce resources.

\section{Effects of Health Sector Reforms: The Case of Maternal and Child Health Care in South Africa}

Have health sector reforms been successful? Some health sector reforms are said to have had a positive effect on the health system goals of efficiency, equity and quality. Berman \& Bossert, (2000:10) assert that only a handful of countries including South Africa, China and Zambia have attempted reforms that have a hope of measurable increase in health equity gains. In South Africa, equity in access might have been achieved in the form of increased utilization of public health facilities Gilson (2002). Comparatively, Columbia and Chile's health insurance systems on the other hand are said to have significant equity problems. Chile's private insurance system for example spends twice as much per capita income as that of the public sector (Berman \& Bossert, 2000:10). This is also true of South Africa where the private sector spends a substantial amount of the health sector budget and supplies a minority of the population. Rakoloti, (2007) confirms this by arguing that there is a huge inequity between the private and public sector. The public sector in South Africa served about 38million people and spent about R52billion in 2006, while the private sector served only 7 million people and it spent about R66billion in the same year on healthcare. 
Amongst all the health sector reform strategies discussed, there is no specific reform strategy that less developed countries must follow. Also, reformers cannot rely on only the models developed in the more industrialized countries. They must draw on ideas and experiences from a wide range of sources and carefully match strategies to the problems they are designed to address (Cassels, 1995:344). This will reduce the negative impacts that some of these strategies may pose on the developing countries.

\subsection{Case Study}

In 1994, maternal and child healthcare in South Africa became free at the point of delivery which was later extended to include free Primary Health Care (PHC) for all citizens using the public health sector. There have been several successes in maternal, child and women's health and nutrition, including: free access to PHC; free health care to pregnant and lactating women and to children under the age of six; prevention of vertical transmission of HIV; high immunization coverage rate due to the Expanded Programme on Immunization (EPI); eradication of deaths due to polio and measles; and implementation of the Choice on Termination of Pregnancy Act and the Primary School Nutrition Programme (Mhlanga, \& Eddie 2008:115).

The impact of the free primary healthcare policy was basically an increase in access to PHC as the financial obstacle to health care was largely overcome, though women and children still had to travel to their nearest PHC site, which could be costly (Mhlanga, 2008:117). The Expanded Programme on Immunization (EPI) has made good progress in increasing coverage with vaccines especially in the following areas:

- maintenance of high immunization coverage rate;

- reduction of neonatal tetanus;

- reduction of deaths from measles with marked

- reduction of measles cases;

- achievement of polio-free status; and

- Implementation of the 'Reach Every District' strategy with community mobilization (Mhlanga, 2008:121).

Although immunization coverage nationally was high according to the 2003 South African District Health and Information System (DHIS), there were districts with only $60 \%$ full immunization coverage, and this resulted in lower coverage overall. The success of the EPI has led to the total elimination of measles deaths and reduction in measles cases among children. In addition, the District Health Barometer (DHB), (2008:7), reports that the average immunization coverage for 2006 was $84.2 \%$. Looking at the most deprived groups, the average immunization coverage in 2007/08 was $81.7 \%$. In the least deprived quintile, however, the average immunization coverage was 12.6 percentage points higher, at 94.3\%. Regarding the provision of essential drugs, Kautzky \& Tollman (2008) cite that progress at policy level has been made with the publishing of national essential medicines list. However access to these medicines in the public sector of developing countries was still inadequate. In other words, thirty years after the Alma Ata conference, the promise of PHC became largely unfulfilled (Kautzky \& Tollman, 2008:18). Some of the challenges include shortage of healthcare workers and poverty.

Furthermore, Gilson \& Mclntyre, (2005:762) posit that the removal of user fees in South Africa has lead to increased healthcare utilization. However this meant unnecessary tensions at primary care level. It resulted in low staff morale and consequently the loss in fee revenue that had been used to supplement staff salaries. Fee removal was not announced in time and as a result, drug supplies were quickly exhausted as utilization increased frustrating health staff and patients. In order to avoid the negative effects of fee removal, it should be accompanied by increased national budgets to ensure that quality is maintained. Careful and deliberate implementation strategies have to follow. Wilkinson et al, (2001: 668) add that the removal of user fees encouraged and increased access to curative services but subsequent clinic congestion and reduced consultation times may have discouraged some women from attending for antenatal care and from bringing their children for growth monitoring and immunization.

A study conducted by the South African Human Rights Commission (SAHRC, 2009:27) stated that as at 2007, $88 \%$ of South Africans were dependent on public healthcare services and in Eastern Cape, about $86 \%$ of people in Eastern Cape were dependent on the public health sector. However, another study by Leatt et al, (2006:52) found that four out of ten children in an Eastern Cape rural site were denied their rights of access to primary healthcare. Poverty was cited as the main barrier to accessing healthcare services. It appears as if the cost of transport is also a significant factor. Some researchers mentioned that the long waiting times at clinics and hospitals proved a strong disincentive for the poor to attend clinics (Leatt et al, 2006:53). Torres, (2001:131) added that the people in rural areas have been especially disadvantaged with regards to access to healthcare. As a result of the inefficiencies that were inherent in the 
public health system, there was a strong disincentive for the poor to attend public clinics (Torres 2001:130). This places a burden on the households to the detriment of their food security which further undermines their health. It is widely accepted that there has been serious shortcomings with the South African health system. This ranges from staff shortages and poor infrastructure, inadequate supplies of medical equipments, medicines and inadequate remuneration. The consequence of this is that the healthcare personnel leave to where there are better conditions. Also, the inequity in primary healthcare continuous to increase which further paralyzes the entire health system.

According to Kautzky \& Tollman, (2008:23) the implementation of developmental policies and the management of $\mathrm{PHC}$ and social services were problematic and appear to lack a coherent strategy. The provincial and local health systems were supposed to be integrated at a district level. These authors point out barriers to the implementation and provision of district based services such as shortage of staff and distributional inequities in the national health system. The new national public health is based on the principles of a primary health care within a decentralized district health system. This new approach employs the principle of distribution of resources equitably meaning that those areas with least resources should be given most assistance (Dalrymple, in Kautzky \& Tollman 2008:23). Furthermore, it places a greater emphasis on helping to prevent disease and promoting good quality health rather than focusing on curative services. Several hospitals In Gauteng province were investigated by a provincial commission of enquiry in Gauteng. Financial constraints were identified as the core problems. There was lack of capacity and infrastructure coupled with growing demand for primary healthcare services. Hospital managers cited the provision of free primary health care and treatment of children under than 5 years as causes of greater pressure on the system. It was suggested that clinics should be more equipped so as to reduce such pressures on hospitals. In the long term, it is aimed that provincial departments are expected to build capacity, monitor the delivery of health services and provide strategic policy directions to the municipalities (Dalrymple, in Kautzky \& Tollman 2008:23).

Further problems of the free maternal and child healthcare policy were that overall high levels of utilization of Antenatal care services and births at utilization masked considerable socio-economic variations. For example $27 \%$ of the poorest women in South Africa give birth at home. Other key issues identified were issues of provider behavior. Although considerable effort had been extended at a policy level with the development of the Confidential Enquiry into Maternal Deaths, the liberalization of the abortion legislation, and development comprehensive guidelines for practice at all levels of the health poor provider practice has been identified as contributing to the majority of maternal deaths in South Africa (NCCEMD in Jewkes et al, 2002). Other studies that have not focused on mortality but on women's experiences of childbirth have also identified problems with provider practice, especially to poor women and teenagers (Jewkes et al, 2002). The devastating impact of AIDS was also identified as a key health system issue. Based on the findings of studies carried out by the Health Systems Trust, South African Health Review, Segall,(2002), Leatt et al(2006) and Schneider \& Palmer, (2002), this paper provides a report of findings that relate to the quality of services provided in public health clinics.

It is suggested by Chopra et al, (2009:3) that the underlying reasons for the almost unabated spread of HIVIAIDS can be largely attributed to weak political leadership, underlying social dislocation, inequality and an uneven fragmented health system. These trends can be attributed to the proportions of maternal neonatal and child health. According to Chopra et al (2009:5), the district hospitals play a pivotal role in maternal and child health delivery but they receive very limited outreach support from the regional hospitals. In addition, recent assessments of maternal and child deaths found that the immediate causes of death were related to delays in seeking care or in finding transport.

\section{Conclusions and Recommendations}

The primary concern of this research paper was to review the progress that has been made in implementing health sector reforms and implications for the free maternal and child healthcare policy. At the moment, there is a high rate of use of maternal and child health services and yet worsening health outcomes in the country. This paper argues that the quality of service delivery in maternal and child health has not been improved with the introduction of the free maternal and child health policy. The paper reinforces the ideas posed by Gilson \& Mclntyre (2005:763) that even though the policy has the potential of reducing social exclusion, it must be managed carefully through supportive actions in order to avoid negative impacts on the wider health system and consequent worsening of the health system. It is also evident that referral systems to higher levels of care such as hospitals are mostly suboptimum and many patients bypass lower levels in order to access higher levels of care. This problem requires attention for optimal solution. Furthermore, improvements in quality coverage require incremental human resource requirements. 
Overall, access to a basic package of maternal and child care is good. For example, $84 \%$ of women give birth in a health facility and $42 \%$ at district hospitals. However, in all levels of facilities, there is an acute shortage of beds and women are discharged six hours after delivery. While it has increased the utilization of Primary Health Care (PHC) clinics, evidence has shown a complete lack of capacity to manage the quality and access to health services. This means there are still differences in the quality of maternal care provided (Schneider \& Gilson, 2000: 93). The challenge facing South Africa is to understand the paradox of supportive policy and funding environments.

\section{References}

AbouZahr C, Wardlaw T. 2004. Antenatal care in developing countries - promises, achievements, and missed opportunities: an analysis of trends, levels, and differentials, 1990-2001. Geneva: UNICEF and WHO joint publication. Available at: http://whqlibdoc.who.int/publications/2003/9241590947.pdf

AbouZahr, C. \& Wardlaw, T. 2001. Maternal mortality at the end of a decade: signs of progress? Bulletin of the World Health Organization. 79:561-573.

Berer, M. 2003. Integration of sexual and reproductive health services: a health sector priority. Reproductive health matters. 11(21):6-15. Berman, P. 1995. Health sector reform: making health development sustainable. Health policy. 32(1-3):13-28.

Berman, P.A. \& Bossert, T.J. 2000. A decade of health sector reform in developing countries: what have we learned. Washington, UNAID.

Borghi, J. \& Ensor, T. 2006. Mobilising financial resources for maternal health. The Lancet. 368(9545):1457-1465.

Braveman, P.A. 2003. Monitoring equity in health and healthcare: a conceptual framework. Journal of Health Population and Nutrition. 21(3):181-192.

Brugha, R. \& Zwi, A. 1998. Improving the quality of private sector delivery of public health services: challenges and strategies. Health policy and planning. 13(2):107.

Buso, D.L. 2004. Public-private health sector mix-way forward. South African Family Practice. 46(9).

Campbell, O.M.R. \& Graham, W.J. 2006. Strategies for reducing maternal mortality: getting on with what works. The Lancet. 368(9543):1284-1299.

Cassels, A. 1995. Health sector reform: key issues in less developed countries. Journal of International development. 7(3):329-347.

Castro-Leal, F.et al. Public spending on health care in Africa: do the poor benefit? Economist. 14(1):49-72.

Chopra et al, 2009. Achieving the health Millennium Development Goals for South Africa: Challenges and priorities. The Lancet 20(374): 1023-31.

Coovadia, H. et al, 2009. The health and health system of South Africa: historical roots of current public health challenges. The Lancet. 374(9692):817-834.

Daniels, N. et al, 2000. Benchmarks of fairness for health care reform: a policy tool for developing countries. Bulletin of the World Health Organization. 78:740-750.

Davanzo, J., \& Adamson, D. (1998). Family planning in developing countries: an unfinished success story. Populations Matters, RANDS Available at: http://www.rand.org/content/dam/rand/pubs/issue_papers/2005/IP176.pdf

De Brouwere, V. \& Van Lerberghe, W. 2001. Safe motherhood strategies: a review of the evidence. ITGPress, Antwerp.

Dmytraczenko, T. et al, 2003. Health Sector Reform: How It Affects Reproductive Health [Online] Available: www.prb.org/pdf/HealthSectorReformbw.pdf 2009 October, 30.

Evans, D.B., et al, 2001. Measuring quality: from the system to the provider. International Journal for Quality in Health Care. 13(6):439.

Gilson, L. \& Mclntyre, D. 2004. Removing user fees for primary care: Necessary, but not enough by itself. Equinet Newsletter. 42.

Gilson, L. \& Mclntyre, D. 2005. Removing user fees for primary care in Africa: the need for careful action. British medical journal. 331(7519):762-765.

Goodburn, E. \& Campbell, O. 2001. Reducing maternal mortality in the developing world: sector-wide approaches may be the key. British medical journal. 322(7291):917

Gwatkin, D.R. 2001. The need for equity-oriented health sector reforms. International journal of epidemiology. 30(4):720.

Hardee, K. \& Smith, J. 2000. Implementing reproductive health services in an era of health sector reform. Policy Project Occasional Papers, Washington, DC: Futures Group International. 4.

Kautzky, K. \& Tollman, S.M. 2008. A perspective on Primary Health Care in South Africa: Primary Health Care: in context. :17-30.

Kelley, E. \& Hurst, J. Health care quality indicators project. Conceptual framework paper. Health Working Papers. 23.

Kerber, K.J., et al, 2007. Continuum of care for maternal, newborn, and child health: from slogan to service delivery. The Lancet. 370(9595):1358-1369

Koblinsky, et al, 1999. Organizing delivery, care: what works for safe motherhood? Bulletin of the World Health Organization. 77:399406.

Leatt, A. et al, 2006. Healing inequalities: The free health care policy. South African Child Gauge. :51-56.

Loewenson, R. \& McCoy, D. 2004. Access to antiretroviral treatment in Africa. British medical journal. 328(7434):241-242.

Lubben, M. et al, 2002"Reproductive Health and Health Sector Reform in Developing Countries: Establishing a Framework for Dialogue," Bulletin of the World Health Organization 80(8): 667-74. 
McIntyre, D. \& Gilson, L. 2000. Redressing dis-advantage: promoting vertical equity within South Africa. Health Care Analysis. 8(3):235258.

McIntyre, D. \& Gilson, L. 2002. Putting equity in health back onto the social policy agenda: experience from South Africa. Social science \& medicine. 54(11):1637-1656.

McIntyre, D., Muirhead, D. \& Gilson, L. 2002. Geographic patterns of deprivation in South Africa: informing health equity analyses and public resource allocation strategies. Health policy and planning. 17(90001):30-39.

Schneider, H. \& Gilson, L. 1999. The impact of free maternal health care in South Africa. Berer M, Sundari Ravindran TK.Safe motherhood initiatives: critical issues.Londres, Blackwell Science.

Schneider, H. \& Palmer, N. 2002. Getting to the truth? Researching user views of primary health care. Health policy and planning. 17(1):32-41.

Segall, M. 1999. Review of public health service delivery: "the bottle is half full" : policy orientated overview of the main findings. Pretoria: Department of Health.

Standing, H. 2002. An overview of changing agendas in health sector reforms. Reproductive health matters.10(20):19-28.

Torres, L. 2000. 'We are Emerging, Slowly and painfully!' Infrastructure Delivery in South Africa.

Weil, O. \& Fernandez, H. 1999. Is safe motherhood an orphan initiative? The Lancet. 354(9182):940-943.

WHO/UNICEF, (1978): Primary healthcare report of the international conference at Alma Ata. Geneva: WHO.

Wilkinson, D. et al, 2001. Effect of removing user fees on attendance for curative and preventive primary health care services in rural South Africa. Bulletin of the World Health Organization. 79:665-671.

World Health Organization (WHO), 2000. World Health Report 2000. Geneva: WHO 
